\title{
Cloud-Aerosol-Turbulence Interactions
}

\author{
Science Priorities and Concepts for a Large-Scale Laboratory Facility
}

Raymond A. Shaw, Will Cantrell, Sisi Chen, Patrick Chuang, Neil Donahue, Graham

Feingold, Pavlos Kollias, Alexei Korolev, Sonia Kreidenweis, Steven Krueger, Juan

Pedro Mellado, Dennis Niedermeier, and Lulin Xue

\section{Workshop to Explore Science Opportunities and Concepts for a Large-Scale Aerosol-Cloud-Turbulence Research Facility}

What: More than 60 scientists from a wide range of fields overlapping with the chemistry and physics of aerosols and clouds in turbulent flows gathered to discuss scientific questions, priorities, and concepts for future laboratory research facilities and associated instrumentation.

When: 21-22 November 2019

Where: Boulder, Colorado

AfFILIATIONS: Shaw, Cantrell-Michigan Technological University, Houghton, Michigan; Chen, Xue-National Center for Atmospheric Research, Boulder, Colorado; Chuang-University of California, Santa Cruz, Santa Cruz, California; Donahue-Carnegie Mellon University, Pittsburgh, Pennsylvania; Feingold-NOAA Earth System Research Laboratory, Boulder, Colorado; Kollias-Stony Brook University, State University of New York, Stony Brook, New York; Korolev-Environment and Climate Change Canada, Toronto, Canada; Kreidenweis-Colorado State University, Fort Collins, Colorado; Krueger-University of Utah, Salt Lake City, Utah; Mellado-Universitat Politècnica de Catalunya, Barcelona, Spain; Niedermeier-Leibniz Institute for Tropospheric Research, Leipzig, Germany 


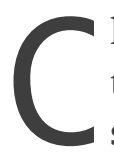
louds and aerosols, ubiquitously embedded in turbulent flows, are central to the prediction of weather and climate. The purpose of the workshop described here was to explore scientific questions and set priorities for a large-scale aerosol-cloud-turbulence laboratory facility. (Here, "facility" denotes one or more aerosol/cloud chambers and the associated instrumentation and technical/scientific staff.) Specifically, at the workshop we attempted to gauge community interest and to obtain a sense of priorities for the scientific challenges likely to be amenable to laboratory investigation. The two overarching questions guiding the workshop presentations and discussion were as follows:

- What pressing scientific questions can we answer with a large-scale aerosol-cloud-turbulence facility that would be difficult or impossible to address otherwise?

- What would a large-scale aerosol-cloud-turbulence facility look like and what measurement capabilities should be associated with it?

The purpose of this meeting summary, therefore, is to outline the range of scientific questions, and the facility concepts that were explored.

We began the workshop with a series of overview talks to highlight scientific questions that could be investigated in a large-scale aerosol-cloud-turbulence laboratory facility. Topics included warm and mixed-phase cloud microphysics, aerosol and cloud chemistry, atmospheric turbulence, radiative transfer, cloud/aerosol instrumentation, and remote sensing. There was ample time for questions and discussion following each overview presentation. We also broke into groups for several hours at various points to enable more active discussion among all participants.

\section{Overview of the need for large-scale laboratory facility for aerosol-cloud-turbulence research}

The workshop began by outlining the benefits of a laboratory facility for aerosol-cloudturbulence interactions:

- well-characterized boundary and initial conditions;

- known inputs, such as aerosol and trace gases;

- ability to measure aerosol and cloud microphysical properties and processes in detail;

- repeatability and/or ability to sample under steady-state conditions, which improves statistical convergence;

- isolation of processes or mechanisms (e.g., ability to minimize large-scale feedbacks); and

- capability for detailed comparison to theory and simulations.

In spite of these compelling advantages, it was noted that there has been a decline of cloud microphysics laboratory studies. For example, the proportion of AMS Cloud Physics Conference abstracts dealing with laboratory studies declined from 40\% in 1976 to 8\% in 2018. One presenter (Korolev) argued that in situ observations have limited capability to enhance existing knowledge on cloud microphysics due to their limited sample volume, uncertain or unknown boundary and initial conditions, and challenges with repeated sampling of the same cloud. In contrast, laboratory studies provide the only practical means to quantify the rates of individual microphysical processes under controlled conditions. Another presenter (Feingold) asked participants to consider when the following quote was published: "Progress in cloud physics has been seriously limited because of the impossibility of conducting controlled cloud experiments on a sufficiently large scale." As contemporary as it sounds, the quote is from a 1952 paper by Ross Gunn (Gunn 1952). 
Participants were asked to read the report of a similar workshop held in the mid-1980s (List et al. 1986) and to consider how the science has progressed since that time, what facilities have been developed, and even what has hindered the achievement of recommendations in that report. Several reasons were discussed for why the timing is right for consideration of a large-scale facility:

- Many of the same science problems still exist.

- The problems are broader: beyond cloud and precipitation physics, they now include aerosol-cloud indirect effects, radiative transfer, aerosol and cloud chemistry, and turbulence interactions.

- New experimental approaches (e.g., turbulent mixing cloud versus expansion chamber) and improved instrumentation for aerosol, cloud, turbulence, and radiation measurements have been developed.

- High-fidelity computational models have emerged that would synergistically interact with a laboratory facility. Such models need to be validated and improved, and the models would also enhance the interpretation of measurements.

Addressing these points, one presenter (Kreidenweis) discussed some achievements and challenges associated with prior laboratory cloud facilities in the United States. The Colorado State University (CSU) dynamic cloud chamber had an inner volume of $1.1 \mathrm{~m}^{3}$ and was used for ice nucleation (DeMott 1990) and stratus cloud simulations (Hindman 1989). Challenges included the inability to find aerosol-cloud-drop closure, a changing environment due to continuous sampling from a relatively small volume, the inability to measure cloud properties within the chamber, and heterogeneities caused by wall effects. The Calspan chamber had a volume of $590 \mathrm{~m}^{3}$ and among other research was instrumental in understanding aerosol processing in cloud cycles, and the quantification of in-cloud sulfate production from $\mathrm{SO}_{2}+$ $\mathrm{O}_{3}$ (Frick et al. 1992). However, the temperature control was limited, precluding the study of ice processes.

The known operational aerosol and cloud chamber research facilities in Asia, Europe, and North America are summarized in Table 1. It was noted that only one chamber is currently operational in North America. The five other U.S.-based chambers described in a recent article by Chang et al. (2016) are all out of operation (including the $590-\mathrm{m}^{3}$ Calspan chamber in New York that was listed then as operational). The chamber types now in operation are predominantly expansion chambers. The ability to adjust wall temperatures dynamically to track the quasi-adiabatic conditions, similar to the former CSU and Desert Research Institute (DRI) chambers in the United States, is available in two chambers. Chambers specifically designed to provide well-characterized turbulence conditions include the turbulent Leipzig Aerosol Cloud Interaction Simulator (LACIS-T; Niedermeier et al. 2020) and the $\Pi$ chamber (Chang et al. 2016).

\section{Science questions and priorities}

Science questions and priorities were discussed in four key areas: boundary layer turbulence and cloud-turbulence interactions (Mellado); aerosol-cloud interactions and warm cloud microphysics (Kreidenweis and Feingold); aerosol and cloud chemistry within a large-scale cloud chamber (Donahue); and mixed-phase cloud microphysics, including aerosol, turbulence, and secondary-ice interactions (Korolev). Their contributions highlight the wide-ranging and rich diversity of scientific problems that would benefit from laboratory investigation. Only a sampling of the topics discussed is reported below.

How can we use laboratory studies to understand the interplay among the various components of the atmospheric boundary layer, including clouds? Turbulence in the boundary layer 
Table 1. Currently operational aerosol-cloud research chambers that were discussed at the workshop. The focus was on chambers that are intended for studying populations of particles, i.e., not flow tubes or wind tunnels that investigate single particles or particles in isolation of each other.

\begin{tabular}{|l|l|l|l|l|}
\hline \multicolumn{1}{|c|}{ Name } & \multicolumn{1}{|c|}{ Volume $\left(\mathrm{m}^{3}\right)$} & \multicolumn{1}{c|}{ Type } & \multicolumn{1}{c|}{ Location } & \multicolumn{1}{c|}{ Status } \\
\hline AIDA & 84.5 & Expansion & Germany (KIT) & 1996-present \\
\hline AIDA-2 & 3.8 & $\begin{array}{l}\text { Expansion with } \\
\text { dynamic walls }\end{array}$ & Germany (KIT) & 2020-present \\
\hline BACIC & 70 & Expansion & China (BWMO) & 2017-present \\
\hline Big Climate Chamber & 3,200 & Expansion & $\begin{array}{l}\text { Russia (Inst. Experi- } \\
\text { mental Meteorology) }\end{array}$ & 1963-present \\
\hline CESAM & 4.2 & Reaction chamber & France (LISA, CNRS) & 2009-present \\
\hline CLOUD & Reaction chamber/ & & \\
\hline LACIS-T & 26.1 & sion to atmos & Switzerland (CERN) & 2006-present \\
\hline MICC & $0.32(2 \mathrm{~m}$ high) & Mixing wind tunnel & Germany (TROPOS) & 2018-present \\
\hline MRI & $18(10 \mathrm{~m}$ high) & $\begin{array}{l}\text { Fall chamber/expan- } \\
\text { sion }\end{array}$ & $\begin{array}{l}\text { United Kingdom } \\
\text { (Manchester Univ.) }\end{array}$ & 2009-present \\
\hline I chamber & 1.4 & $\begin{array}{l}\text { Expansion with } \\
\text { dynamic walls }\end{array}$ & $\begin{array}{l}\text { Japan (Meteorologi- } \\
\text { cal Research Inst.) }\end{array}$ & 2005-present \\
\hline
\end{tabular}

can be far from homogeneous and isotropic even at meter and submeter scales (Katzwinkel et al. 2012; Jen-La Plante et al. 2016). This inhomogeneity is important for supersaturation and particle size distributions, for example. Though direct numerical simulation can provide 3D turbulent fields, other processes are not easy to simulate or are still not understood theoretically, such as nucleation, chemistry, radiation, surface roughness, etc. It was noted that one problem ripe for laboratory study is mixing across a cloud interface or capping inversion, and especially its influence on supersaturation and aerosol activation and cloud droplet growth in the entrainment zone. How sedimentation and phase changes affect such mixing and the entrainment velocity are crucial unknowns.

A longstanding challenge in cloud physics has been to understand the onset of precipitation in warm clouds, including activation, condensation, collision-coalescence, and effects of giant cloud condensation nuclei. This question is also intimately related to how cloud processing modifies aerosol particles. It was noted that collision-coalescence is an example of a problem that can be studied in the laboratory using "bottom-up" or "top-down" approaches: the former is to construct collision kernels from individual droplet pairs, whereas the latter involves looking at input and output (initial, final) droplet size distributions and inverting to obtain the collision kernel. These concepts can be extended to precipitation and scavenging efficiency.

From the chemistry perspective, the presence of turbulence implies the existence of covariance, which is relevant in a host of atmospherically relevant problems: temperature and chemical species (e.g., because of temperature dependence of reaction rates), binary nucleation (covariance between two chemical species), and soluble trace species and cloud liquid water (transport through clouds). The formation of new particles in cloud-influenced regions is an example (Williamson et al. 2019). The condensation sink controls the steady state and time scale (Westervelt et al. 2014; Donahue et al. 2019) and is therefore crucial to understand. Many of these problems have been explored in detail, but usually in a laminar, not turbulent, flow. 
Basic problems in the microphysics of mixed-phase clouds include the very definition of mixed-phase cloud (as opposed to adjacent regions of liquid water and ice), the spatial scales of interaction between ice particles and liquid droplets, the conversion rate of liquid to ice, the time for glaciation, and the roles of vertical velocity and turbulence on the maintenance of mixed-phase clouds. Laboratory investigation is still needed for understanding aspects of single ice particle growth, such as the metamorphosis and growth rate of ice particles under varying temperature and supersaturation, as well as particle settling velocities. Problems involving the collective growth of cloud particles (both liquid and ice) and secondary ice production are even more numerous. Examples include mechanisms of aggregation and the environmental conditions for secondary ice initiation.

During the breakout sessions, an even wider variety of scientific questions and challenges was identified. One key challenge is how we justify the chamber size as a downscaling or as a comparable scale to various atmospheric cloud processes. As one strategy to address the challenge, participants were asked to identify unsolved scientific topics and assign a length scale to these topics (time scales were converted to length using the phenomenology of the turbulence energy cascade). Table 2 summarizes the most important questions that emerged in the general topic areas of "aerosol/cloud chemistry," "aerosol-cloud interactions," "mixedphase/cold clouds," "radiative transfer," and "turbulence-microphysics interactions." Science topics are organized in the table from smallest to largest scales, in multiples of 10. It is immediately evident that the topic areas span the entire range of scales. The $10-\mathrm{m}$ scale was predominant, with 22 science questions, with 12 for 1-m scales and 15 for 100-m scales. We take this as a practical identification of the most useful scales to be explored. This feedback, which was the product of extensive discussion, is one of the key outcomes of the workshop.

\section{Opportunities for measurement technology and computation}

A primary motivation for considering the development of a large-scale facility for aerosolcloud-turbulence interactions is the phenomenal advancement of measurement and computational capabilities. Three aspects were reviewed during the workshop.

Significant science opportunities now exist for remote sensing methods that could be applied within a large-scale cloud chamber (Kollias). Ultra-high-resolution (centimeter-scale) measurements using active remote sensing represent a new measurement frontier in atmospheric research. For example, ultra-high-resolution radar (Schmidt et al. 2012, 2019) could allow detection of individual hydrometeors while submillimeter wavelength radars can offer centimeter-scale resolution (Cooper and Chattopadhyay 2014). High-resolution photon timetagging lidar observations have been demonstrated with a range resolution of $4 \mathrm{~mm}$ (BartonGrimley et al. 2018), and cloud layer features have been observed with $26 \mathrm{~cm}$ bin width. Remote sensing can also serve as a nonintrusive method to reduce the influence of instrumentation on the chamber environment. On the other hand, a large-scale cloud chamber could also help reduce uncertainties in hydrometeor remote sensing in the atmosphere. A topic ideal for remote sensing methods and of great current relevance is retrieving the fall velocity of various hydrometeor classes in a turbulent environment. In short, rapid developments in instrumentation and signal processing could provide a leap forward in cloud chamber observational capabilities from 3D imaging of individual hydrometeors for spatial distribution and motion of hydrometeors, to water vapor and temperature measurements.

Certain cloud/aerosol instrumentation and measurement challenges are unique to a largescale facility (Chuang). The ideal measurement would include hydrometeor and aerosol size, shape and composition, as well as 3D fluid velocity and fluid thermodynamic properties within 10-100-cm-scale samples. These measurements would be especially compelling if made in a Lagrangian setting, for example, on a 3D translation mount with feedback to measured velocity. Recent advances in the measurement of velocity fields (e.g., particle tracking and 
Table 2. Example scientific questions in five cloud-related fields, organized by relevant spatial scale. Each of the five fields is color coded. The total number of topics in each scale is given in the second row of the table: the 10-m scale is adequate to address a majority of the questions in the laboratory.

\begin{tabular}{|c|c|c|c|c|c|c|}
\hline Research area & Science questions & $<1 \mathrm{~m}$ & $1 \mathrm{~m}$ & $10 \mathrm{~m}$ & $100 \mathrm{~m}$ & $1,000 \mathrm{~m}$ \\
\hline & Number of science questions & 9 & 12 & 22 & 15 & 5 \\
\hline Aerosol/cloud chemistry & Aqueous photochemistry (particle scale) & $\mathrm{x}$ & & & & \\
\hline Aerosol/cloud interactions & Do we know enough about heterogeneous ice nucleation? & $\mathrm{x}$ & & & & \\
\hline Aerosol/cloud interactions & $\begin{array}{l}\text { Do we know enough about droplet activation? Influence of chemical } \\
\text { (composition) and physical properties (charge, shape)? }\end{array}$ & $\mathrm{x}$ & & & & \\
\hline Mixed-phase/cold clouds & $\begin{array}{l}\text { Rate of growth/evaporation of different types of ice crystals under con- } \\
\text { stant and varying environmental conditions including metamorphosis }\end{array}$ & $x$ & & & & \\
\hline Radiative transfer & Light scattering by single ice crystal and aggregates & $\mathrm{x}$ & & & & \\
\hline $\begin{array}{l}\text { Turbulence-microphysics } \\
\text { interaction }\end{array}$ & $\begin{array}{l}\text { How does turbulence affect collision coalescence; sedimentation, ori- } \\
\text { entation, and rotation of non-sphere (ice crystal) particles; ice process, } \\
\text { diffusional growth? }\end{array}$ & $\mathrm{x}$ & & & & \\
\hline Aerosol/cloud interactions & $\begin{array}{l}\text { What is the relationship between cloud/turbulence properties and aerosol } \\
\text { scavenging? }\end{array}$ & & $\mathrm{x}$ & & & \\
\hline Mixed-phase/cold clouds & Aggregation-varying temperature and humidity conditions & & $x$ & & & \\
\hline Mixed-phase/cold clouds & Terminal velocity of hydrometeors & & $\mathrm{x}$ & & & \\
\hline Mixed-phase/cold clouds & Secondary ice production & $\mathrm{x}$ & $\mathrm{x}$ & $\mathrm{x}$ & & \\
\hline Mixed-phase/cold clouds & Primary ice formation and its dependence on turbulence & & $x$ & $x$ & & \\
\hline Radiative transfer & Radiative cooling at Sc cloud top with droplet growth (interface chamber) & & $x$ & $x$ & & \\
\hline Radiative transfer & RT through electric field oriented ice particles & & $\mathrm{x}$ & $x$ & & \\
\hline $\begin{array}{l}\text { Turbulence-microphysics } \\
\text { interaction }\end{array}$ & $\begin{array}{l}\text { How turbulence-induced fluctuation of concentration fields affects drop- } \\
\text { let size distribution (sedimentation/vertical velocity). Four main foci: 1) } \\
\text { supersaturation, 2) fall speeds, 3) clustering, 4) collision-coalescence }\end{array}$ & & $\mathrm{x}$ & $\mathrm{x}$ & & \\
\hline Mixed-phase/cold clouds & $\begin{array}{l}\text { Aggregation of ice under varying relative humidity and temperature } \\
\text { conditions, including effect of charge }\end{array}$ & & & $\mathrm{x}$ & & \\
\hline Mixed-phase/cold clouds & $\begin{array}{l}\text { Rate of partitioning of phase in mixed-phase clouds, conversion of ice } \\
\text { phase to mixed-phase clouds due to convection }\end{array}$ & & & $\mathrm{x}$ & & \\
\hline $\begin{array}{l}\text { Turbulence-microphysics } \\
\text { interaction }\end{array}$ & $\begin{array}{l}\text { Coarse-grain microphysics at the } 10 \text {-m scale (for coupling to LES, sam- } \\
\text { pling measurements, etc.) }\end{array}$ & & & $\mathrm{x}$ & & \\
\hline $\begin{array}{l}\text { Turbulence-microphysics } \\
\text { interaction }\end{array}$ & What scales of fluctuations are most important for diffusional growth? & $x$ & $\mathrm{x}$ & $\mathrm{x}$ & $\mathrm{x}$ & \\
\hline Aerosol/cloud interactions & $\begin{array}{l}\text { What are the optimal aerosol characteristics for inducing marine cloud } \\
\text { brightening? }\end{array}$ & & $\mathrm{x}$ & $\mathrm{x}$ & $\mathrm{x}$ & \\
\hline Radiative transfer & Exploring emerging remote sensing techniques & & $\mathrm{x}$ & $x$ & $\mathrm{x}$ & \\
\hline Aerosol/cloud chemistry & Aqueous photochemistry (cycling, parcel scale) & & & $x$ & $\mathrm{x}$ & \\
\hline Aerosol/cloud chemistry & Parcel scale dynamics of activation interacting with turbulence & & & $x$ & $x$ & \\
\hline Aerosol/cloud chemistry & Interstitial scavenging & & & $x$ & $\mathrm{x}$ & \\
\hline Aerosol/cloud interactions & $\begin{array}{l}\text { How are aerosols entrained/detrained at the cloud interface? How does } \\
\text { turbulence influence aerosol entrainment into the cloud? }\end{array}$ & & & $\mathrm{x}$ & $\mathrm{x}$ & \\
\hline Aerosol/cloud interactions & What is precipitation susceptibility as a function of aerosol properties? & & & $x$ & $x$ & \\
\hline Radiative transfer & Imaging through turbulent clouds & & & $x$ & $x$ & \\
\hline Radiative transfer & Depolarization by particle shape and multiple scattering & & & $x$ & $x$ & \\
\hline $\begin{array}{l}\text { Turbulence-microphysics } \\
\text { interaction }\end{array}$ & Measure entrainment rates & $\mathrm{x}$ & $\mathrm{x}$ & $\mathrm{x}$ & $\mathrm{x}$ & $\mathrm{x}$ \\
\hline Aerosol/cloud chemistry & Precipitation scavenging & & & $\mathrm{x}$ & $\mathrm{x}$ & $\mathrm{x}$ \\
\hline Radiative transfer & Particle correlation inducing deviations from Beer-Lambert & & & $x$ & $\mathrm{x}$ & $\mathrm{x}$ \\
\hline Radiative transfer & Aerosol effect on cloud albedo (e.g., given heterogeneity in drop distance) & & & $x$ & $x$ & $x$ \\
\hline Radiative transfer & Signal propagation through an optically thick cloud & & & & $\mathrm{x}$ & $\mathrm{x}$ \\
\hline
\end{tabular}


laser-induced fluorescence) are prime for adaptation to a cloud physics chamber environment. It was also noted that measurement of supersaturation has persisted as a significant challenge.

One of the most compelling reasons to consider a large-scale facility now was highlighted in the discussion of current computational capabilities. High-performance computing now allows resolution of turbulence and aerosol/cloud microphysics with much higher accuracy so that intercomparison of detailed simulations can be made with laboratory measurements (Chen). On the one hand, computational models can be verified against the laboratory measurements to reduce the uncertainty coming from the representation of aerosol-cloud dynamics and physics. On the other hand, the comparison is also beneficial to experimentalists, because access to detailed models allows investigation of processes or quantities difficult to observe with existing instruments (e.g., supersaturation). It is also an economical way to design and test new experiments. Problems that are ideal for investigation with synergistic modeling and laboratory approaches include hydrodynamic interaction and collision rates, giant CCN effects including hygroscopic cloud seeding, turbulence effect on droplet condensation, aerosol processing, ice formation in mixed-phase stratocumulus, and even radiative properties of cirrus (e.g., ice crystal complexity and verification of radiation schemes).

\section{Facility concepts and workshop recommendations}

In the second set of breakout sessions, participants were asked to explore facility concepts. Specifically, they were asked to consider ranges of spatial and temporal scales needed for scientific questions, instrumentation needs, and interaction with modeling efforts. As facility concepts were discussed, two aspects were emphasized.

First, the importance of experiments and facility designs guided by dimensionless variables was stressed. To achieve an atmospheric interpretation inside the chamber, it is not necessary to exactly mimic a natural system, but rather to consider relative scales through the use of some well-known variables, for example, Reynolds, Rayleigh, and Stokes numbers, and mean free path (for photons or particles) relative to chamber dimension. For sampling flows and particles from a fixed-volume chamber, it was noted that (volume sampling rate $\times$ experiment time scale)/(volume of chamber) should be much less than unity. For problems related to turbulence in stably stratified flows, the chamber size relative to the Ozmidov scale was suggested as a relevant parameter. Finally, in the context of flows relevant to the atmospheric boundary layer, the ratio of surface moistening versus entrainment drying was highlighted.

The second point of emphasis, as already alluded to above, is the critical role of numerical simulation in guiding the design of future facilities, as well as to explore how laboratory results can be scaled to atmospherically relevant scenarios. Fully exploring and testing a range of large-scale facility concepts and scales using high-fidelity models will be crucial. The computational models will need to be verified against laboratory measurements to ensure proper understanding of boundary conditions and their impact on the measured variables, such as wall effects on temperature/vapor fields and particle loss rates. Finally, models can provide guidance on what measurements can be made, and where they should be located.

Discussion at the workshop was free-flowing and explored a wide range of ideas for research facilities. As expected from a group of over 60 scientists representing a variety of disciplines, there was not full convergence on one chamber type. No single facility is suitable for investigation of all scientific questions, and one takeaway message from the workshop was the exciting opportunity that would arise from having a site with multiple interacting chambers within a single facility, where instrumentation and expertise could be shared. Beyond merely having multiple chambers instead of a "one size fits none" compromise, such a design could permit a fusion between answering scientific questions in one area (i.e., chemistry and physics governing new-particle formation and growth) and another (i.e., the boundary condition of particle size and composition distributions for studies of cloud droplet activation). 
Four concepts emerged with significant levels of support, and we briefly describe them here in no order of priority.

Convection chamber. A large chamber with a warm, wet bottom surface and a cool, wet top surface leads to turbulent Rayleigh-Bénard convection with supersaturation generated through isobaric mixing. This is the mode of operation of the $\Pi$ chamber, which has been used for studies of activation, aerosol processing, and cloud droplet and ice condensation growth in a turbulent environment. Scaled up sufficiently (e.g., height of 5-10 m, compared to $1 \mathrm{~m}$ for the $\Pi$ chamber), such a cloudy convection chamber could be used for investigations of turbulence effects on droplet growth by collision-coalescence, secondary-ice generation, and radiative transfer through clouds.

Piston-type expansion chamber. As shown in Table 1, there are a number of expansion chambers in existence. One variation on this concept would be to have an expansion with a fixed mass of air, rather than through exhaust of the pumped air. This would allow multiple cycling of cloud formation and evaporation and the associated aerosol processing.

Mineshaft cloud chamber. Many problems in cloud physics and radiative transfer involve long pathlengths, for interaction of falling hydrometeors in the former, and propagation of photons in the latter. A design concept that was discussed repeatedly throughout the workshop is a tall tower or, for even larger scales, a vertical mineshaft. If the facility has a sufficiently large vertical extent, cloud formation could be induced through the reduction in pressure with height, similar to what occurs in the atmosphere. Indeed, mineshafts that are hundreds of meters deep could be available. The role of losses of heat and water vapor to the walls in such a geometry would need to be explored.

Stratified mixing layer. Cloud-top entrainment is a problem of sufficient importance that many participants felt that it merits a facility specifically designed for cloud-clear air mixing in a stratified environment. One possibility would be a horizontal wind tunnel with lower and upper sections where cloud and above-cloud thermodynamic conditions would be set (similar to a larger, horizontal LACIS-T). The cloud could be artificially generated using sprays, or, in one brainstorm configuration, it could be fed by the outflow of a mineshaft cloud generator.

As the concepts were discussed by the group, one participant from another field sketched some of the ideas while listening. We found that the resulting diagram captured the range of ideas very well, so we have reproduced it here as Fig. 1. Not all ideas are shown, but the four main concepts that emerged are illustrated.

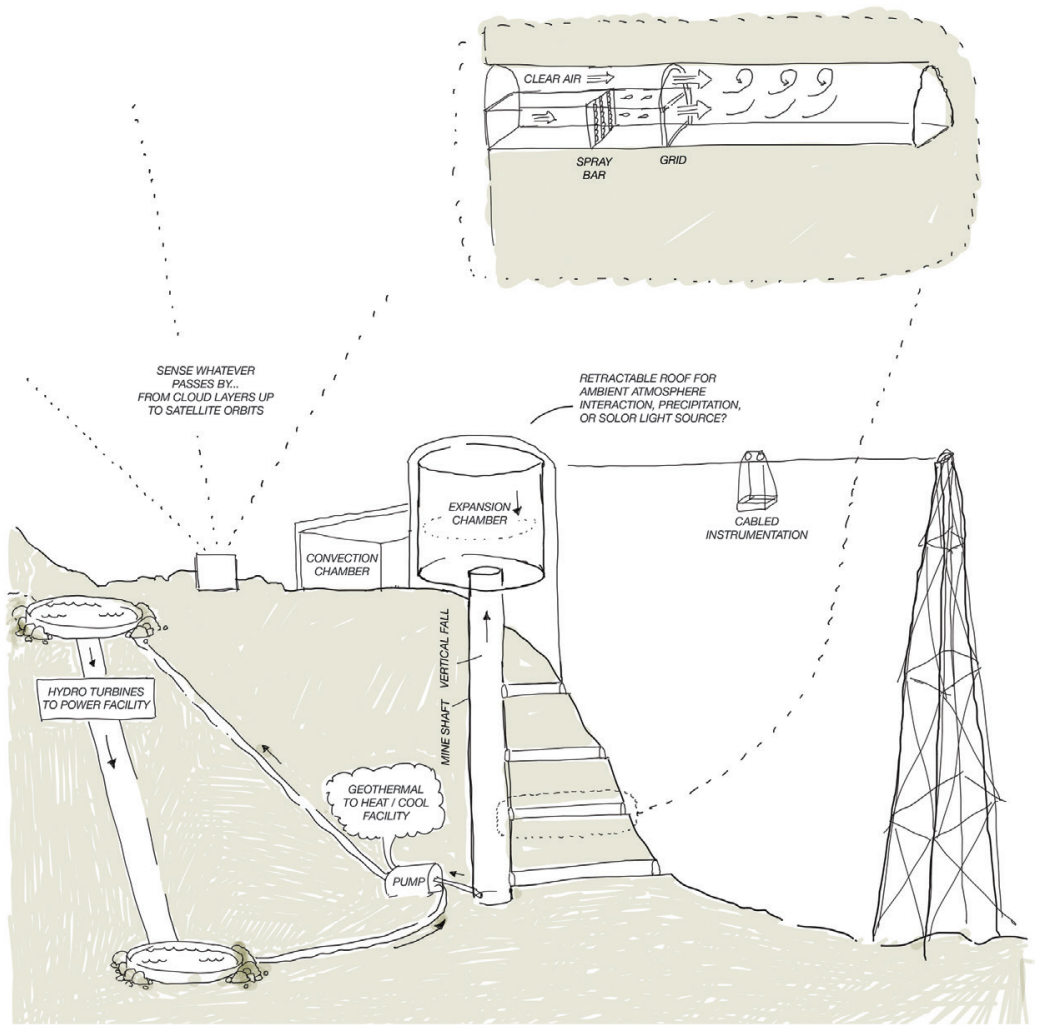

Fig. 1. An informal sketch of four chamber concepts discussed in the workshop: convection chamber, piston expansion chamber, vertical mine shaft, and stratified mixing layer. Several other synergistic components are also illustrated. See text for further description. 
The vertical mineshaft cloud chamber is shown in the center. Directly above it is a piston-type expansion chamber. To the left of that is a cloud-convection chamber. On the upper right is a conceptual drawing of a horizontal wind tunnel for studies of entrainment and mixing in a stratified flow. In the spirit of a general cloud research facility, a traverse for studying natural clouds is shown, as well as a remote sensing station for measuring higher cloud layers. It was noted that an advantage of collocation of laboratory and field facilities is the sharing of instruments between them. Remote sensing techniques used and verified in the chambers could also be tested in the natural environment for comparison. As an example of the kinds of broader impacts that could be considered, the artist also depicted hydro and geothermal systems that would allow a "green" method for power generation and heating/cooling within the laboratory facility.

The overriding sentiment of the workshop was that there is a strong need for a significant investment in laboratory cloud and aerosol research facilities in order to improve weather prediction models and climate simulations. The ultimate goal of a cloud-aerosol-turbulence facility will be the development of next-generation, physically based parameterizations for microphysical processes in cloud and climate models. Laboratory research therefore plays a crucial role in catalyzing numerical simulation and in situ observations for further progress in our understanding of cloud processes. Access to a large-scale cloud-aerosol-turbulence facility is envisioned as especially important to the North American scientific community.

Acknowledgments. The National Science Foundation (NSF) provided the funding support for this workshop through Grant AGS-1945681. We are grateful to the following: Susannah Burrows (Pacific Northwest National Laboratory), Hermann Gerber (Gerber Scientific), and Fan Yang (Brookhaven National Laboratory) for looking over the meeting summary for accuracy; Jessica Brassard of Michigan Technological University for invaluable support and advising on the strategy, organization, and logistics of the workshop, as well as for the artistic musings shown in Fig. 1; Peter Sullivan and Wojciech Grabowski for facilitating the coordination and co-sponsorship by the Geophysical Turbulence Program; Kris Marwitz of NCAR for administrative and logistical support; and to the more than 60 attendees who actively engaged in brainstorms and discussions, without whom this meeting summary would not have been possible. Further workshop details, including the full list of participants, are available at https://sites.google.com/mtu.edu/aerosol-cloud-facility-workshp 


\section{References}

Barton-Grimley, R. A., R. A. Stillwell, and J. P. Thayer, 2018: High resolution photon time-tagging lidar for atmospheric point cloud generation. Opt. Express, 26, 262030-262044, https://doi.org/10.1364/OE.26.026030.

Chang, K., and Coauthors, 2016: A laboratory facility to study gas-aerosol-cloud interactions in a turbulent environment: The $\prod$ chamber. Bull. Amer. Meteor. Soc., 97, 2343-2358, https://doi.org/10.1175/BAMS-D-15-00203.1.

Cooper, B., and G. Chattopadhyay, 2014: Submillimeter-wave radar: Solid-state system design and applications. IEEE Microwave Mag., 15, 51-67, https://doi. org/10.1109/MMM.2014.2356092.

DeMott, P. J., 1990: An exploratory study of ice nucleation by soot aerosols. J. Appl. Meteor., 29, 1072-1079, https://doi.org/10.1175/15200450(1990)029<1072:AESOIN>2.0.C0;2.

Donahue, N. M., W. Chuang, and M. Schervish, 2019: Gas-phase organic oxidation chemistry and atmospheric particles. Organic Oxidation and Multiphase Chemistry, J. R. Barker, A. L. Steiner, and T. J. Wallington, Eds., Advances in Atmospheric Chemistry, Vol. 2, World Scientific, 199-317, https://doi. org/10.1142/9789813271838_0004.

Frick, G. M., W. A. Hoppel, J. W. Fitzgerald, and B. J. Wattle, 1992: A cloud chamber study of the effect which nonprecipitating clouds have on the aerosol size distribution. U.S. Naval Research Laboratory Rep. NRL/FR/4212-92-9514, 47 pp.

Gunn, R., 1952: A vertical shaft for the production of thick artificial clouds and for the study of precipitation mechanics. J. Appl. Phys., 23, 1-5, https://doi. org/10.1063/1.1701971.

Hindman, E. E., 1989: Formation and optical properties of a warm cloud in a slow-expansion cloud chamber. J. Atmos. Sci., 46, 3653-3663, https://doi. org/10.1175/1520-0469(1989)046<3653:FAOPOA>2.0.CO;2.
Jen-La Plante, I., and Coauthors, 2016: Physics of Stratocumulus Top (POST): Turbulence characteristics. Atmos. Chem. Phys., 16, 9711-9725, https://doi. org/10.5194/acp-16-9711-2016.

Katzwinkel, J., H. Siebert, and R. A. Shaw, 2012: Observation of a self-limiting, shear-induced turbulent inversion layer above marine stratocumulus. Bound.Layer Meteor., 145, 131-143, https://doi.org/10.1007/s10546-011-9683-4.

List, R., J. Hallett, J. Warner, and R. Reinking, 1986: The future of laboratory research and facilities for cloud physics and cloud chemistry. Bull. Amer. Meteor. Soc., 67, 1389-1397, https://doi.org/10.1175/1520-0477-67.11.1389.

Niedermeier, D., J. Voigtländer, S. Schmalfuss, J. Schumacher, R. A. Shaw, and F. Stratmann, 2020: Characterization and first results from LACIS-T: A moist-air wind tunnel to study aerosol-cloud-turbulence interactions. Atmos. Meas. Tech., 13, 2015-2033, https://doi.org/10.5194/amt-13-2015-2020.

Schmidt, J. M., and Coauthors, 2012: Radar observations of individual rain drops in the free atmosphere. Proc. Natl. Acad. Sci. USA, 109, 9293-9298, https:// doi.org/10.1073/pnas.1117776109.

- , and Coauthors, 2019: Radar detection of individual raindrops. Bull. Amer. Meteor. Soc., 100, 2433-2450, https://doi.org/10.1175/BAMS-D-18-0130.1.

Westervelt, D. M., J. R. Pierce, and P. J. Adams, 2014: Analysis of feedbacks between nucleation rate, survival probability and cloud condensation nuclei formation. Atmos. Chem. Phys., 14, 5577-5597, https://doi.org/10.5194/acp14-5577-2014.

Williamson, C. J., and Coauthors, 2019: A large source of cloud condensation nuclei from new particle formation in the tropics. Nature, 574, 399-403, https:// doi.org/10.1038/s41586-019-1638-9. 